\title{
Merab Babukhadia
}

Ivane Javakhishvili Tbilisi State University

\section{"Trialogue" System Efficiency in Second Language Teaching}

\begin{abstract}
The article is the first attempt of an original method, studying a second language in a group evidence of effectiveness and superiority of "the theory of trialogue", in particular, compared with the method of teaching in the dialogue.
\end{abstract}

Keywords: the theory of trialogue second language speech learning theory; Original, methodological innovation.

In teaching Georgian as a second, foreign language methods many textbooks have been written in recent years, which, frequently, conform to modern standards of the contemporary Georgian language teaching and will move forward and made a solid basis for the methodology to further refinement and development of the base form. However, in our view, substantial changes are necessary for the improvement of teaching methods, in particular in terms of the practical application of studying language. The practical use of the language is the key to the maximum concentration. During the years I worked with TSU students and, in particular, the experience of working with the Azeri students have been predetermined it.

It should be noted that a few decades ago published readers and textbooks didn't take into consideration depth and precision of language mastering for foreign students needs.

The main task of teaching a second language is to communicate, which actually sets the learning process (Hu, huakhin, 2008). This, in turn, means that the language actually needs to use oral and written communication with the order. Our approach and the daily lessons meant only real, living language teaching. Real life contexts - living materials and not artificial, fictional texts learning... 
Students always need to be reminded of this objective, which means that if you make the grammatical mistakes, but your understanding is possible, and you can understand what your interlocutor tells you, consider that the objectives themselves have been overwhelmed. But, if you can translate the whole text and grammar tests easily, but you can't even pronounce a sentence, then your learning had serious flaws. Make use of this challenge, one of the main types of work, there must be a constant foreign language study - work with trialogues.

Trialogue group classes allow full use of the speech, which is the maximum involvement of students in an intense speech.

What does trialogue mean? Below we will try and explain exactly determine, what is it and what are the advantages of the dialogue speech in comparison with trialogue.

For modern Pedagogical Sciences one of the most acute problem is effective use of dialogue language method. Teaching of modern languages in the second stage of the study can not provide unfettered speech dialogue conversation. That is the reason for a more rational and efficient methods of analysis of the speech due, on the formation of skills (Tyler, Ralph, 2008). At the same time, a second language learning process more interesting and fun to be provided to its abettors.

The speech dialogue is not so long since established itself as an independent aspect of the speech development. Therefore, the many issues that the theoretical and experimental research requires the use of assumptions, in particular, the relationship between speech dialogue and monologue transfer of the course, the selection of situations, which is the basis of teaching in different stages; During the lecture, speaking establishing the speaking situation, selecting material for dialogue.

Theoretical and methodological research of this article is to analyze the speech dialogue terms, speaking method of teaching to explain the idea; Psycho-linguistic characteristics of speech dialogue revealing; Methods and techniques of speech dialogue second language studies; Exercises and a methodical recommendation package of dialogue speech.

This requires dialogue speech learning process, evaluation and synthesis methods theoretical considerations.

The practical value is determined by use of the second language teaching.

Speech dialogue has many features. Here is concentrated the speech samples, expression, whole linguistic structures that are used for monologue speech.

The study is essentially alive dialogue relations simulator, which is the essence of real conversation, with conversational cliché and constructed phrases. Only trialogue training be able to successfully use in practice. Despite in the scientific literature traditional personal division has a serious alternative - since E. Benvenist from (Benvenist, 1974) till 
nowadays and the subjects and objects are mentioned as a initiator, executor, agence, patience and benefactive (T. Uturgaidze, 2002), meanwhile in the learning process, they still remain traditional and resolutely subject and objects. We should not be ignored in traditional grammar personal division.

Until now, the dialogue was and is considered (particularly fair enough) one of the powerful means of communication through language, where the third person is involved in sporadic and depends on the teacher's mood when he speaks. However, the actual speech and motor speech reasoned with its rare use even turn into a serious obstacle. Followed by a speech deepening inferiority complex is even more difficult to reverse and lies as the physiological barrier on the student.

To fill this gap, we need to study the interactive method supersede dialogue speech (question-reply) method, where the third person in the same ratio to the second person, this is a solid basis convert the speech of the gap - the third person speech practice exclusion or the use of very low frequency. This is proved by the speech dialogue, where the other person is the frequency of use of the motor speech within the first and second person. Accordingly, teaching dialogue speech is speech dialogue plus a third person, the other person equals the specific weight.

This time a couple of practical examples would be enough that such examples are legion, and the all around in our Guide to "speak in English" (M. Babukhadia, 2014):

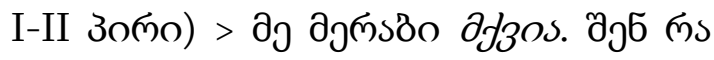

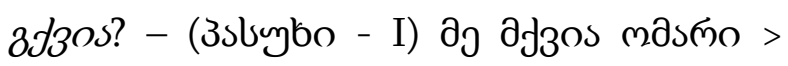

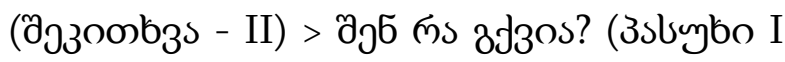

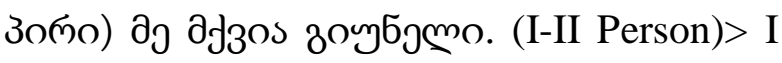
Merab name. What is your name? (Answer - I) My name is Omar> (Answer II) My name is Gunnel> (Question - II) What is it? > (Answer

- II) her name is (she is called) Gunnel> (Answer - II) his name is (he is called) Omar

The above scheme is not complete, but very defective. The third person ignore is the main source of speech defectiveness, fragmented introduction and claudicating. If the information can not be fully accepted, it could be issued fully as well.

Alongside trialogue speech allows eliminated all the defect, which is characterized by foreign students and usually easily be pulled out, which is given as a theory from the practice and not on the contrary, and very briefly and in a transparent manner. Grammatical boredom is represented as an attractive simple formula (although we think that it is not necessary there to give some grammatical formulas):

\section{For example:}

My name is Omar - no, Omar-i ( $\mathrm{i}$-is a nominative case mark in Georgian, which is not find in Indo-European languages), 


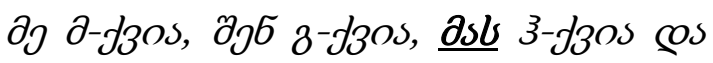

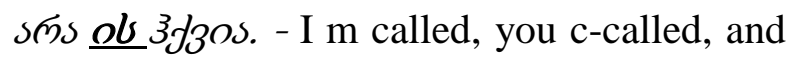
not he, she, it is called. That is where we have $\mathrm{m}, \mathrm{g}, \mathrm{h}$ or zero personal sign, there's going to have $\underline{\partial s \downarrow}$,him, her, in subjective system - he,

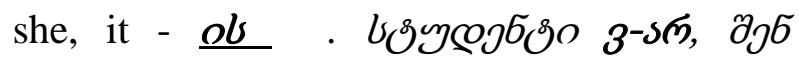

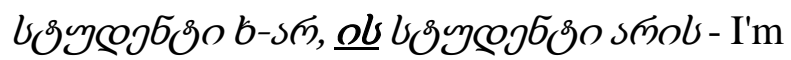
a student, you are a student, he, she, is a student.

In short, the schematic, we would write:

a -

$\begin{array}{ccc}8^{-} & & \text {him/his } \\ 3- & \text { or } & 0\end{array}$

$3^{-}$

0- he, she

$-b$ m -

g - him/his

$\mathrm{h}$ - or 0

0 - he, she

$-\mathrm{S}$

I repeat, this can only be made in case of students' interest. Well, it is best to refrain from formulas and schemes and increase the intensification of material supply, we get much better results...

Finally, the trialogue speech is the original theory and the innovation in speech group studying. It establishment in correct speaking and its motorizing would be promote a big progress. It fills the gap and speech dialogue gives you the chance to study the language fully mastering. 


\section{References}

Babukhadia, 2014 - Babukhadia, speak Georgian (Azerbaijani and Armenian students) A1 level, Tb. 2014.

Benvenist, 1974 - Э. Бегнвенист. Общая лингвистика, М., 1974.

huakhini, 2008 - Hu, huakhini, Xu, Huaxin. "My Personal Philosophy in Teaching English as a

Second Language: Some Methods I Used in Teaching English to Chinese Freshmen in Xi

'a Foreign Language University." 2008.

Tyler, 2008 - Tyler, Ralph, Tyler, Ralph W. "Nature of Learning Activities." Review of Educational

Research. Vol. 1, No. 1, pp. 22-29. The Curriculum. Jan 1931. Jstor. 22Mar 2008.

Uturgaidze, 2002 - Uturgaidze Tedo, grammatical categories and their Correlation in Georgian verb, Tb., 2002. 